
Azizeh K. Sowan*
Department of Health Restoration \& Care Systems Management, School of Nursing, University of Texas Health Science Center at San Antonio, San Antonio, TX, USA
Dates: Received: 11 September, 2015; Accepted: 14 December, 2015; Published: 16 December, 2015
*Corresponding author: Azizeh K. Sowan, PhD, RN, Department of Health Restoration \& Care Systems Management, School of Nursing, Suite 2.628, 7703 Floyd Curl Dr. - MC 7975, University of Texas Health
Research Article

\section{Applying IT-Related Business Process Reengineering In an Informatics Course for Graduate Nursing Programs} Science Center at San Antonio, San Antonio, TX 78229-3900; Tel: +1-210-567-5799; Fax: +1-210-5671719; E-mail: sowan@uthscsa.edu

www.peertechz.com

Keywords: Nursing informatics; Graduate nursing programs; Nursing education; Business process reengineering

ISSN: 2581-4265

\begin{abstract}
Introduction: Studies on methods of teaching informatics for graduate nursing programs are limited. This paper discusses the design and evaluation of an IT-related Business Process Reengineering (BPR) Project, one of the main assignments in an informatics course offered jointly for three graduate nursing programs. Challenges and lessons learned are also presented.

Methods: Informatics and Patient Care Technology is a 3-credit, 16-week, hybrid, core graduate course that addresses advanced leadership roles in the clinical setting related to information systems. The course was developed based on IT Essentials of professional organizations. From Spring 2013 to Fall 2015, a total of 117 graduate nursing students were enrolled. IT-related BPR is a 7-week assignment designed using Adesola and Baines's (2006) BPR Implementation Framework to equip students with informatics skills necessary to lead IT improvement projects. Students evaluated the course in a reflective journal by answering 11 essay questions and via the IDEA system (Individual Development and Educational Assessment). Content analysis of narrative data was performed to categorize themes and trends concerning the IT-related BPR project.

Result: Almost all students (115/117) indicated that the IT-related BPR assignment was very valuable and provided overwhelmingly positive feedback about the technical and professional skills learned. Knowledge transfer and understanding the complexity of healthcare organizations were the main subcategories under professional skills. Main challenges were related to variability in computer skills to complete the technical aspects of the assignment.

Conclusion: Designing a student-centered assignment based on a systemic thinking approach and Programs' Essentials and empowering students as process owners with IT and leadership skills and tools are successful strategies for technical and professional development in informatics. Course modification is a continuous improvement process guided by new trends in heath and science, as well as students' needs, feedback and success in completing the learning activities.
\end{abstract}

\section{Abbreviations}

AACN: American Association of Colleges of Nursing; DNP: Doctor of Nursing Practice; BSN-PhD: Bachelor of Science in Nursing to Doctor of Nursing Philosophy; BPR: Business Process Reengineering; DMAIC: Define, Measure, Analyze, Improve and Control; QSEN: Institute of Quality and Safety Education in Nursing; NONPF: National Organization of Nurse Practitioner Faculties; MSN: Master of Science in Nursing; SWOT: Strengths, Weaknesses, Opportunities and Threats; EMR: Electronic Medical Record; IDEA: Individual Development and Educational Assessment.

\section{Introduction}

Health IT is the largest growing investment in the healthcare industry and an essential component for safe and quality care [1]. Thus, "preparing a workforce capable of innovating, implementing, and using health communication and IT is critical to healthcare success" [1]. Informatics is one of the core competencies for healthcare professionals along with providing patient-centered care, working in interdisciplinary teams, employing evidence-based practice, and applying quality improvement [2]. Informatics competencies are developed at different levels of nursing programs and expertise [35]. Professional nursing organizations called for the integration of informatics into the nursing curriculum and specified IT-related Essentials [6,7].

Much of the research in informatics education and competencies discussed curriculum development of degree-based biomedical informatics programs [8-10], general informatics competencies required for nurses and nursing students at different levels of practice and programs $[4,5,11]$, information literacy as one of the informatics competencies [12], and strategies employed by graduate programs to meet the American Association of Colleges of Nursing's (AACN) IT-related Essential [13]. Very few studies discussed how to teach informatics for graduate nursing programs. These were limited to a specific master track [14], or a doctor of nursing practice (DNP) program [15], or were abstracts without sufficient details on course design and delivery processes [16]. In these studies, learning activities were not sufficiently described to a level that can be replicated by other schools. 
At the University of Texas Health Science Center San Antonio's School of Nursing, we offer a joint informatics course for our Master, post-master DNP, and Bachelor of Science in Nursing to Doctor of Nursing Philosophy (BSN-PhD) programs. The course addresses advanced leadership roles in the clinical setting related to information systems and patient care technology. Course content focuses on informatics competencies, new trends in informatics, IT-related business process reengineering, consumerization in healthcare, IT safety, and legal and ethical issues related to information systems. A detailed description of the course will be presented elsewhere. This paper discusses the process of designing and evaluating an IT-related Business Process Reengineering Project, one of the main assignments in the course. Challenges and lessons learned are also presented. We hope the description will provide guidance to health students who lead IT projects, educators who teach informatics, and healthcare clinicians involved in optimizing IT processes.

The term Business Process Reengineering (BPR) is used interchangeably with Business Process Improvement and is defined as "the fundamental rethinking and radical redesign of business processes to achieve dramatic improvements in critical, contemporary measures of performance, such as cost, quality, service and speed" [17]. As a quality improvement approach, BPR shares similar principles with Lean Thinking in that it is used to optimize quality, safety, efficiency, cost, and flow of a process by eliminating non-value added steps. BPR also follows implementation frameworks similar to Six Sigma, such as the DMAIC (Define, Measure, Analyze, Improve, and Control) methodology [18].

In healthcare, the BPR methodology was used to streamline and improve safety and efficiency of processes such as drug and supply, medication discount, patient admission [19,20], and computer-aided surgery [21]. According to Rosemann and colleagues, BPR becomes a "foundation for contemporary management approaches" [22]. This holistic end-to-end process management approach evaluates and optimizes a process from a systemic perspective considering the culture of change, infrastructure, resources and organization mission.

\section{Materials and Methods}

\section{Course description}

Informatics and Patient Care Technology is a 3-credit, 16-week, hybrid, core graduate course, and the only informatics course offered for graduate nursing studies at our School of Nursing. The main objective of the course is to equip students with IT skills necessary to function as change leaders in IT projects from a system perspective. The course was developed based on the AACN's DNP Essential IV related to IT and patient care technology [6], the Institute of Quality and Safety Education in Nursing's (QSEN) informatics competencies [23], and the National Organization of Nurse Practitioner Faculties' (NONPF) Technology and Information Literacy Competencies [7]. The course was designed and delivered using Blackboard Learn 9.1. From Spring 2013 to Fall 2015, the course was taught in five semesters with a total enrollment of 117 graduate nursing students divided as: 23 DNP, 91 MSN (Master of Science in Nursing) and 3 $\mathrm{BSN}-\mathrm{PhD}$. The maximum enrollment was 30 students per a section. Students had clinical expertise in primary, acute, and chronic care in private practices and military, veterans, and governmental health care systems.

\section{Description of the IT-related BPR assignment}

IT-related BPR is a 7-week assignment designed to equip students with informatics skills necessary to lead IT improvement projects. Adesola and Baines's [24] BPR Implementation Framework was adapted as a standardized and systematic approach to design the assignment (Table 1).

The project consists of six phases (Figure 1). Students have one week to complete each phase. Each phase targets specific informatics skills (Table 2). The first three phases of problem identification and organizational assessment using SWOT (strengths, weaknesses, opportunities, and threats) and snapshot analyses are essential to understanding the business needs according to Adesola and Baines's framework [24]. Phase 4, modeling the as-is process, matches the second and third steps in Adesola and Baines's framework to understand, model, and analyze the process [24]. Modeling the tobe process is to be completed in phase 5 to redesign the process. In this project, and because of time constrains, students are not required to implement the proposed change. Therefore, the last three steps in Adesola and Baines's BPR framework related to implementation, assessment and evaluation of the new process [24] are limited in the course to describing a plan for improvement, evaluation, and sustainability (Table 1).

The initial step in the assignment is to identify a "business process" by answering the question: which clinical or administrative process is not fully supported by the IT system in use and is compromising safety and quality or introducing workflow inefficiency?

Phase 1 of the project starts by the problem identification as a core for any IT improvement initiatives. The steps of this phase are described in Table 1. Problems should be pertinent to clinical patient care or administrative IT systems in use. Administrative IT systems were included to individualize the assignment and promote applicability, specifically since some students work at the executive level and do not directly use clinical patient care technologies. Students need to identify and differentiate between an IT problem and the resulted clinical or administrative problem. IT problems may include, but are not limited to, issues in data structure, knowledge presentation, locating or retrieving information, missing guidelines or assessment processes in the electronic medical record (EMR), failure of care transition/coordination as a result of a lack of systems connectivity or interoperability across the different units/ departments in the organization, and missing decision support systems, alerts or reminders to minimize errors and improve quality. Clinical or administrative problems should be a result of the IT problem. For example, students may use high sepsis rate as a clinical problem and relate it to the lack of embedded sepsis protocol in the EMR, as the IT problem. Other steps of this phase include conducting a comprehensive literature search to discuss the significance of the clinical problem, providing data-driven evidence of the size and impact of the problem in the unit or organization of practice, and providing detailed description of the clinical setting and the IT system in use. 


\begin{tabular}{|c|c|c|c|}
\hline Step & Step Description & Techniques & Our Adaptation \\
\hline \multirow[t]{2}{*}{$\begin{array}{l}\text { Understand business } \\
\text { needs }\end{array}$} & \multirow[t]{2}{*}{$\begin{array}{l}\text { - Develop vision and strategic } \\
\text { objectives } \\
\text { - Perform competitor analysis } \\
\text { - Develop organizational model } \\
\text { - Evaluate current practices } \\
\text { - Prioritize objectives } \\
\text { - Scope change } \\
\text { - Establish measurable targets } \\
\text { - Develop process objectives and } \\
\text { assess readiness } \\
\text { - Obtain approval and initial project } \\
\text { resource } \\
\text { - Benchmark the process }\end{array}$} & \multirow[t]{2}{*}{$\begin{array}{l}\text { - Organization model } \\
\text { - SWOT analysis } \\
\text { - Force field analysis } \\
\text { - Readiness assessment } \\
\text { - Stakeholder analysis } \\
\text { - Process prioritization } \\
\text { matrix } \\
\text { - Pareto analysis } \\
\text { - Process performance } \\
\text { table }\end{array}$} & $\begin{array}{l}\text { Phase 1: Problem Identification } \\
\text { - Problem statement } \\
\text { - Literature search: } \\
\text { - Significance of the clinical problem (extent and impact) } \\
\text { - IT and non-IT-related solutions to the problem } \\
\text { - Considerations when implementing the specified IT solutions (e.g., } \\
\text { expected negative consequences or technology hazards) } \\
\text { - Size and impact of the problem in student's own setting of practice by } \\
\text { utilizing findings from databases } \\
\text { - Objectives of the assignment } \\
\text { - Detailed description of the facility (setting) and unit of practice } \\
\text { - Detailed description of the IT system in use } \\
\text { - IT problem statement } \\
\text { - Detailed description of elements of the IT problem }\end{array}$ \\
\hline & & & $\begin{array}{l}\text { - Phase 2: Organizational Assessment: SWOT analysis } \\
\text { - SWOT analysis } \\
\text { - Organization-driven data that support SWOT analysis }\end{array}$ \\
\hline $\begin{array}{l}\text { Understand the } \\
\text { process }\end{array}$ & $\begin{array}{l}\text { - Identify business process } \\
\text { architecture } \\
\text { - Scope and define process } \\
\text { - Capture and model the 'as is' } \\
\text { process } \\
\text { - Model the process }\end{array}$ & $\begin{array}{l}\text { - XPat process } \\
\text { - IDEF0 } \\
\text { - Walkthrough } \\
\text { - Process flowchart } \\
\text { - ABC } \\
\text { - Cause and effect analysis }\end{array}$ & $\begin{array}{l}\text { - Phase 4: Model and Describe the As-is Process } \\
\text { - Swim lane the current workflow of the clinical or administrative nursing } \\
\text { process } \\
\text { - Identify steps where clinical and IT problems exist }\end{array}$ \\
\hline $\begin{array}{l}\text { Model and analyze } \\
\text { process }\end{array}$ & $\begin{array}{l}\text { - Verify and validate model } \\
\text { - Measure existing process } \\
\text { performance } \\
\text { - Analyze business process }\end{array}$ & - Value added analysis & $\begin{array}{l}\text { - Narrative description of the process } \\
\text { - Value added analysis } \\
\text { - Verify and validate the model }\end{array}$ \\
\hline Redesign process & $\begin{array}{l}\text { - Benchmark the process } \\
\text { - Identify performance criteria for } \\
\text { redesign process } \\
\text { - Identify focus of redesign activity } \\
\text { - Model and validate the 'to be' } \\
\text { process } \\
\text { - Identify IT requirements } \\
\text { - Estimate performance of } \\
\text { redesigned process }\end{array}$ & $\begin{array}{l}\text { - Benchmarking } \\
\text { - Creative silence workshop } \\
\text { - Brainstorming }\end{array}$ & $\begin{array}{l}\text { - Phase 5: Model and Describe the To-be Process } \\
\text { - List all possible solutions and pick the best solution to redesign process } \\
\text { - Identify performance criteria for redesign process } \\
\text { - Identify and justify the focus of redesign activity } \\
\text { - Model and validate the to-be process } \\
\text { - Identify IT requirements } \\
\text { - Estimate performance of redesigned process } \\
\text { - Identify and justify the value added versus non-value added processes }\end{array}$ \\
\hline $\begin{array}{l}\text { Assess new process } \\
\text { and methodology }\end{array}$ & $\begin{array}{l}\text { - Conduct process deployment and } \\
\text { performance data reflections } \\
\text { - Revise organizational approach }\end{array}$ & $\begin{array}{l}\text { - Action plan } \\
\text { - Evaluation measurement } \\
\text { report } \\
\text { - Customers measurement } \\
\text { survey }\end{array}$ & \multirow[t]{2}{*}{$\begin{array}{l}\text { - Expected barriers and facilitators } \\
\text { - Cost benefit analysis } \\
\text { - Evaluation and sustainability plan }\end{array}$} \\
\hline Review New Process & $\begin{array}{l}\text { - Develop strategic view of } \\
\text { business } \\
\text { - Set process targets and } \\
\text { performance } \\
\text { - Develop plan to meet targets } \\
\text { - Implement plan }\end{array}$ & $\begin{array}{l}\text { - Process improvement } \\
\text { matrix }\end{array}$ & \\
\hline
\end{tabular}

SWOT: Strengths, weaknesses, opportunities and threats; XPat process: eXpert Process Knowledge Analysis Tool; IDEF0: Integration DEFinition; ABC: activity based costing. The Business process reengineering implementation framework was adapted and included in this paper with permission from Dr. Adesola, A. [24].

Phase 2 consists of developing the SWOT analysis, a business strategic planning tool that helps identify internal factors that positively affect organizational growth and improvement (strengths and opportunities) and external factors that may hinder an improvement (weaknesses and threats) [25].

The system snapshot analysis is prepared in Phase 3 and is based on Alter's Work Systems Theory [26]. Students analyze the nine elements of the snapshot (Figure 1). According to Alter, processes and activities, participants, information, and technologies are the four elements within the work system, therefore; are usually analyzed at the microsystem level [26]. Customers and products/services elements can be inside or outside the work system, therefore; are analyzed at the micro, meso and/or macrosystem level based on the student work environment and the identified problem. Environment, infrastructure, and strategies are elements outside the work system with direct effects on the work system, and should be analyzed at the 


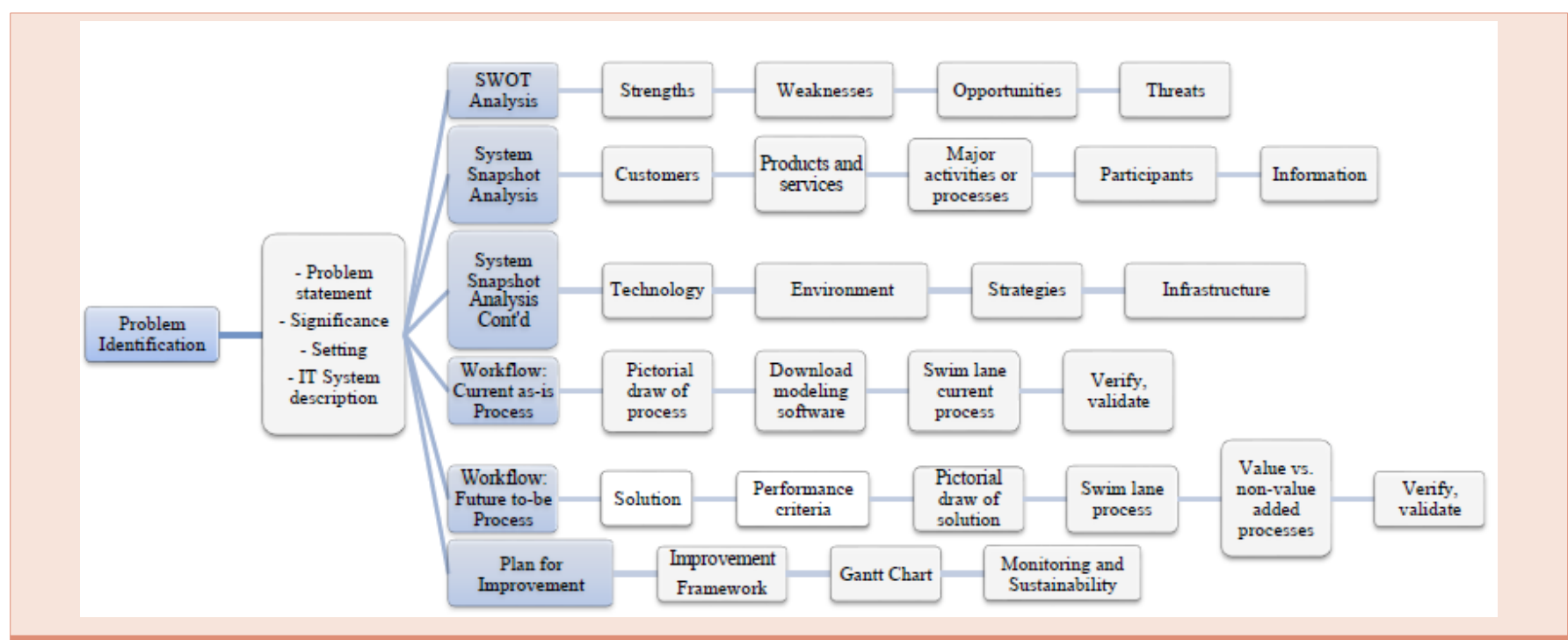

Figure 1: Steps of the IT-related Business Process Reengineering Project. The project consists of 6 phases starting by the problem identification and ending by plan for improvement.

Table 2: Informatics skills taught in the course.

\begin{tabular}{|c|c|}
\hline Project Phase & Informatics Skills \\
\hline \multicolumn{2}{|l|}{ Phase 1: Problem Identification } \\
\hline Identification of IT problem & $\begin{array}{l}\text { - Identify health IT-related unsafe, inefficient, or inappropriately workflow-integrated practices (problem) } \\
\text { - Identify and present work system (facility) data to support the impact and size of a clinical problem }\end{array}$ \\
\hline $\begin{array}{l}\text { Significance of the problem on } \\
\text { practice }\end{array}$ & $\begin{array}{l}\text { - Information literacy skills concern searching and retrieving recent and relevant evidence to support the significance of the } \\
\text { problem }\end{array}$ \\
\hline \multicolumn{2}{|c|}{ Phase 2 and 3: Organizational Assessment } \\
\hline SWOT & \multirow{2}{*}{$\begin{array}{l}\text { - Use business tools to support IT projects } \\
\text { - Investigate and analyze IT issues from a mico, meso, and macrosystem perspectives/levels } \\
\text { - Understand IT infrastructure and strategies of the healthcare organization }\end{array}$} \\
\hline Snapshot & \\
\hline \multicolumn{2}{|c|}{ Phase 4 and 5: Swim Lane a Process Workflow } \\
\hline Swim lane a process & $\begin{array}{l}\text { - Know ones own personal computer specifications } \\
\text { - Pick the appropriate swim lane software that matches the personal computer specifications } \\
\text { - Download the trial version } \\
\text { - View tutorials and use the application: pick the appropriate template and symbols, divide/add/delete lanes, add connections, } \\
\text { - correct mistakes, save/export the diagram } \\
\text { - Incorporate a workflow diagram into the assignment's Microsoft Word document }\end{array}$ \\
\hline Discuss a plan & $\begin{array}{l}\text { - Use a theoretical framework to guide IT processes redesign } \\
\text { - Decide on the appropriate performance and sustainably measures to evaluate an IT project }\end{array}$ \\
\hline Gantt chart & - Create and present a Gantt chart using Excel or workflow software \\
\hline Poster presentation & $\begin{array}{l}\text { - Information presentation } \\
\text { - Create and submit e-posters with voiceover }\end{array}$ \\
\hline
\end{tabular}

meso and/or macrosystem level. Environment includes factors such as policies, procedures, mission, vision, history, and environmental culture. Infrastructure includes human and technical resources managed outside the work system (e.g., quality improvement or IT departments). Strategies include organization, department, or unit strategies. Strategies at the three levels should align to provide a balanced work system. System snapshot is an excellent framework to analyze a work system from a system perspective and an essential component for BPR success. Internal and external participants and customers include all stakeholders in the organization.

The results of the structured organizational assessment using
SWOT and system snapshot analyses are incorporated in the improvement plan (last phase of the project). The first three phases of the project should be data-driven based on organizational data to support them. Students are to obtain these data from their department or other departments such as IT, quality, risk, or administration.

In Phase 4, students model the current or as-is functional workflow using the appropriate swim lane software. A swim lane is a diagram that illustrates the relationships between a business process and the functional process owners (actors or participants) and/or departments operating that process. A process is illustrated using specific phases of the task and the exact activities. Gaps in the process 
(problems) are highlighted. Workflow modeling is a major phase of the project. Computer and navigation skills required to complete this phase are described in Table 2. Examples of swim lane flowchart software are Visio, SmartDraw, ConceptDraw PRO, Grapholite, and Creately. Students choose the appropriate software based on type and version of their personal computer's operating system, whether Mac or Microsoft Windows. Students use the free-access trial version of the software to avoid expenses and test the product before any intention to purchase for future use. Students verify and validate their models (Table 1) with their colleagues, leaders, and classmates through presenting the model on a class discussion board.

The fifth Phase of the project is to model and discuss the to-be process. The discussion includes identification and justification of value added activities and the need to eliminate non-value added activities.

The sixth and last Phase is the improvement plan. In this phase, students discuss the plan to carry out the change and implement the to-be process using a theoretical framework to guide a systematic change. Developing and presenting a Gantt chart for the implementation process is a requirement. A Gantt chart is a project management bar chart that illustrates phases and activities of the change, resources required (e.g., cost, time), and personnel involved. Basically, it describes the what, who, when and how much. In the discussion, students are to synthesize the information from the organizational assessment and use it as a foundation to justify activities in the improvement plan and to identify all required technical, information and human resources and change strategies (e.g., leadership support, communication, training and capacity development if required), discuss expected barriers and facilitators, provide cost benefit analysis, and describe a clear measurement (performance) matrix, sustainability and monitoring framework.

After project completion, students are to make a presentation about their projects. This could be done using oral poster presentations or e-posters with voiceover.

\section{Pedagogical strategies}

The instructor used different strategies to promote timely and successful completion of the IT-related BPR assignment by students [27]. Strategies include:

1. Clear expectations. Clear expectations about the assignment were communicated at the beginning of the course in a face-to-face meeting with students. These expectations were also detailed in an introductory module in Blackboard. For example, although the assignment started week five in the course calendar, students were expected to think about the IT problem statement the first day of class.

2. Early approval of the core phase of the project. While the project was designed to be completed in successive phases, it was interrupted in the second phase by another assignment for the instructor to approve the submitted problem statements as the core phase of the assignment and for students to revise their problem statements if needed.

3. Early preparation for and group work on the modeling process. Students attended a face-to-face session to model the process. Students were asked to select and download the swim lane software, try the software, draw a pictorial of the process, and come to class prepared to model the process using the software. Students were grouped based on the software selected and completed the modeling process in pairs or groups of three.

4. Multiple submissions and timely feedback. Students completed the assignment in four submissions to keep them on track and received continuous and timely feedback on each submission.

5. Instructor support. The instructor was available to support students with technical problems for assignment completion (e.g., the use of the swim lane software).

6. Sharing experiences. Students discussed different phases of their projects in a short format with their classmates using the discussion board. This was extremely beneficial for students to modify their projects, and most important to know about different clinical and administrative IT systems used in different institutes. In the discussion, they shared experiences on how the same process is implemented and optimized at different facilities.

7. Examples of the end product. Different examples of completed assignments were posted for students to see how the end product should look.

\section{Assignment evaluation}

As one of the course requirements, at the end of each semester students evaluate the course using 11 essay questions and post their evaluation in a journal in Blackboard system. Evaluation questions target the extent to which the course helped students meet their professional objectives, most and least useful learning activities, course workload, most important informatics and professional skills gained, effectiveness of the discussion threads and blogs, topics students wish to learn more about, and overall course experience. Additionally, students evaluate the course anonymously and voluntarily at the end of each semester using the IDEA (Individual Development and Educational Assessment) School of Nursing's Course Evaluation System. Course evaluation in IDEA system is a rating scale of the effectiveness of the pedagogical strategies with a free-text area for narrative comments. Content analysis of students' feedback from the reflective journal and their comments submitted via IDEA system was performed to identify common themes. The comments about the IT-related BPR project were analyzed separately and presented in this paper.

Under the "overall course experience" evaluation question, students were asked to report challenges in assignments' completion. The instructor also logged the challenges indicated by students while completing the project in their e-mails, phone calls, office appointments, and the face-to-face class when students attended to model their workflow. All challenges faced by students while completing the IT-related BPR assignment were analyzed.

The reflective journal of the course evaluation was assigned 3 
points (out of 100 points total course grade), in order to encourage students to submit responses. The grade was assigned based on the number of questions answered. The instructions encouraged students to provide objective responses in a professional manner, whether positive or negative, and to suggest ways for improvement. The instructions emphasized the main purpose of the course evaluation, which is to improve future courses based on students' needs, and that negative responses will not affect the grade of the reflective journal or any other grade in the course. To maintain objectivity, another faculty with a previous experience in teaching informatics randomly reviewed $20 \%$ of students' submissions on course evaluation using the reflective journal and compared them to the final themes.

\section{Results}

During the five semesters of teaching the course, all students from the three programs completed the project successfully. Students' projects covered a wide range of critical areas in informatics, such as the need for systems integration, documentation improvement, screening tools for preventive care, better care coordination, transition and follow up, health databases for public schools, and databases for professional nursing development.

All students evaluated the course using the reflective journal ( $100 \%$ response rate). Less than $50 \%$ of students in each semester anonymously evaluated the course using the IDEA system. Most of students' comments submitted to IDEA system were brief and general addressing issues such as workload, instructor support, or their overall experience and rarely target specific assignments. Therefore, the results of content analysis were mainly based on the reflective journal. The other faculty supported all the themes based on her review of $20 \%$ of the journals.

In general, almost all students from all programs (115/117) indicated that the IT-related BPR assignment was very valuable and provided overwhelmingly positive feedback about the skills learned from this assignment. Students' comments were categorized under technical and professional skills (Table 3).

The majority of students (110/117) realized the importance of the technical skills learned in leading improvement initiatives, such as creating a Gantt chart, downloading and using a swim lane software to model a business process, presenting data in tables and charts, and preparing an e-poster with voiceover (Table 3). Students from all programs were also very pleased about the professional skills learned (113/117). The most common comments were on knowledge transfer and realizing the complexity of healthcare organizations, reported by 61 and 60 of the 117 students, respectively. Students spoke to the fact that this assignment correlates perfectly with their clinical practice and shared their plans to present their projects to their institutes and implement the change (35/117). Students highlighted the sophisticated level of the assignment that matches the level of systemic thinking required for graduate students. They further wished they had the course early in their programs to use these skills in other courses (52/117).

The assignment helped students better understand how different departments function within their organizations and the available organizational data. Students highlighted the value of SWOT and system snapshot tools to understand the complexity of work systems' functions and the interconnections at the micro, meso and macrosystem levels. Some of them reported their unawareness of the existence of an informatics department and specialized nursing informaticists in their institutes (10 students) and others grasped a better understanding of the role of the IT department in their institutes in systems development, support and maintenance (27 students). Students realized the need for interprofessional collaboration in improvement projects for quality and safer care and the complexity of changing practice.

Table 3: Categories of students' comments concerning the IT-related BPR assignment $(\mathrm{N}=117)$.

\begin{tabular}{l|l}
\hline $\begin{array}{l}\text { Categories } \\
\text { (Number of students) }\end{array} \quad$ Examples of Students' Comments \\
\hline
\end{tabular}

Technical skills (110)

Modeling software

E-poster with voiceover

Gantt chart
Data presentation

"Learning how to complete a swim lane, snapshot and SWOT analysis were extremely useful assignments for project management. Putting the poster presentation together with a voiceover were very useful, and I would have to say my favorites"

"Be open to self-learning a new software program was amazing"

"Gantt chart was a great organization and visualization of an improvement plan"

"This assignment forced me to leave my comfort zone and learn how to use the many tools required to create the tables and charts that served as visual representations of the data collected"

\section{Professional Skills (113)}

Plans for knowledge transfer (61)

\footnotetext{
"This was useful to my department because it is a problem that many nurses struggle with and to devise a potentially viable plan for change is a true accomplishment"

"SWOT, Gantt chart, snapshot, swim lane skills are translatable to real work settings and I actually having the opportunity to use them in my current work setting"

"In our break room right now, there is a new suggestion board to improve the flow of our daily activities. I will suggest my paper on double charting and discuss ways to improve safety"

"I plan on presenting my entire project to the office manager soon and believe the visuals I can present will really help her see the importance of purchasing a barcode medication scanner"

"I hope all students bring their ideas to their management and IT professionals. I plan to as well because that is how improvements happen and how health IT grows and provides better and safer care for our patients"

"This project is designed for a graduate level, it requires system-based thinking and is the type of project that I will implement in real life"

"I wished this course was given at the beginning of the DNP program, the information gained would have benefited me a lot in in other courses"
} 
Valuing the complexity of a change (30)

\section{Effective knowledge} healthcare organizations (60)

Presentation (29)

"After many and many years of work experience, I felt that I just now realized the complexities of my organizations' functions, I had to make many contacts and see how other departments' such as IT, quality, administration, etc. contribute to nursing, safety and quality care"

"SWOT and snapshot were very valuable to understand the complexity of my organization"

"Work system theory is a great framework for organizational assessment and guiding change"

"I learned that there is an actual Nurse Informatics Role within my hospital"

"Now I gained a better understanding to what informatics does in my hospital"

"I gained insight into who comprises the informatics team and what they are responsible for"

"Professionally I developed a relationship with my hospital informatics dept. and plan to utilize this relationship to help me troubleshoot future suggestions or problems"

"This class has taught me to reach out to different people in order to collaborate and gain information so that my business improvement plan was comprehensive and realistic. This has taught me that in the future, various departments and professionals must constantly work together to provide thorough care for my patients to ensure they are receiving quality, safe care at all times" "It helped me figure out how a project of that scale comes together and that it would require the effort of persons from multiple disciplines to work in unison"

"I have not, in 7 years at the VA, sought out answers or help from IT or public affairs in order to gather data. This proved very insightful, if not always helpful"

"Business improvement was most helpful because I got a better and fuller picture of the entire process and helped develop a better understanding of how much effort it can take for one single project to launch"

"I never thought it takes all these resources to plan for a change"

"Allowed me to develop skills for a poster presentation"

"I enjoyed creating my poster presentation and listening to other students' presentation"

"I never used voiceover in PPT, it was a challenge, but felt so proud when I completed it and listened to my presentation"

"Presenting all phases of my project in 10 minutes was tough but excellent exercise to be succinct"

Understanding the business process (20)
"I had never seen myself as the 'process owner' and never realized the complex connections between nursing and other healthcare processes. Mapping a process and all other phases were a great eye opener to realize the bigger business picture"

"I never thought of nursing processes as 'business' processes"

"Thinking from a business perspective forced me to think of any process as an investment"

"The term business opened my eyes to the commitment we have toward improvement"

"As a business process now I am thinking of the big picture, how this process can survive within the large business"

SWOT: Strengths, weaknesses, opportunities and threats.

Effective knowledge presentation using e-posters with voiceover was an enjoyable skill reported by 29 of the 117 students. Students also acknowledged the change in their view of everyday nursing processes (20/117). From a business perspective, they viewed themselves as a key process owner and realized other owners in the process, understood that nursing processes are part of a bigger picture, viewed business processes as investment, and identified the need for continuous process improvement within complex organizations.

In their comments, students also highly appreciated the pedagogical strategies used to promote timely and successful completion of this project. Specifically, they provided overwhelmingly positive comments about how: (1) submitting the project in phases helped them manage their time (50 students/117), (2) discussing the phases of the assignment with their classmates in the discussion board supported their learning to know about other IT systems and how other facilities approach IT systems improvements (30 students), and (3) the face-to-face session to model the workflow helped them in this phase of the project and how grouping them was a valuable strategy to work together and collaborate in software use, specifically, those with a lower computer literacy (15 students).

\section{Challenges}

The great variability in students' computer skills resulted in some difficulties to complete the technical aspects of this assignment. These include difficulty in (1) using Excel to create a Gantt chart (38 students/117). These students indicated that they do not usually use Excel in their work or program of study to create charts. Students also faced difficulties in (2) creating and posting the e-poster with voiceover (20/117), (3) matching the modeling software to their computers' technical features to download the software (16 students/117), (4) navigating the software appropriately (10/117), and (5) copying and pasting the diagram to their assignment document (10/117).

\section{Discussion}

The early recommendation to integrate informatics into the nursing curriculum was issued in the 1970's [28]. Three decades later, the National League of Nursing reported that informatics is not yet well integrated into the curricula of many schools of nursing [29]. Although the situation might be different in 2015, little information spoke to the current state of informatics integration into nursing and health curricula.

Teaching informatics skills is based on the availability of 
informatics experts and the methods by which schools envision achieving the IT-related programs' Essentials. To date, different schools of nursing do not offer specific courses in informatics for their undergraduate or graduate programs, but rather deploy informatics skills to be taught across different courses. On the other hand, a recent study provided evidence on the lack of specialized nurse informatics faculty in the graduate programs of the US nursing schools [13].

Preparing a workforce capable of making major contributions to high-tech complex work environments by evaluating and redesigning healthcare IT is essential for workforce readiness. At the graduate level, organizations such as the AACN and NONPF outlined Essentials to guide the development of the DNP and MSN programs $[6,7]$. The challenge is to integrate these competencies in a meaningful experiential and student-centered way. Our findings showed that the IT-related BPR assignment provided students with the appropriate informatics and leadership skills to lead IT projects from a business systemic perspective. Modeling the process created a sense of ownership and avoided soloed by mapping the cross disciplinary roles in business processes, as reported by students. Students analyzed the problem and proposed an improvement plan from a micro, meso and macrosystem perspectives by collaborating with other departments at their institutes to support a data-driven problem. The change of students thinking of everyday nursing processes to business processes was invaluable achievement of this assignment. This encouraged students to think outside the box, appreciate the complexity of maximizing the value of and streamlining a single process, and view nursing processes as investment that requires continuous improvement. Equally important, students reported a strong intention to transfer the knowledge gained from this assignment and to implement the projects in their work settings and use the IT and leadership tools in other courses. Although we did not follow students to examine actual implementation of the projects, the skills students learned from this assignment proved to be very valuable in that students employ in other courses and their graduation projects. Different faculty members informed the course instructor that many students started using workflow modeling, SWOT, system snapshot and Gantt chart in other courses and in their graduation projects. The Directors of the Master and DNP programs were very pleased about the quality of students' graduation projects and encouraged all students to use these tools. Additionally, to date, three of the DNP students used the topics of the IT-related BPR project as their Capstone graduation projects.

Designing a student-centered assignment was a major factor for the assignment success. Each student applied the phases of the project based on current IT systems in use. Equally important was the instructor support and adaptation of the assignment based on available resources and students' needs. For example, In Spring 2014, students presented the project in a poster day conducted at the School of Nursing and attended by the Dean and graduate faculty. Because of time and budget constrains (i.e., arranging for the poster day and renting poster boards) and in order to expand the informatics skills (Table 2), the course instructor changed the presentation method to e-poster with voiceover in subsequent semesters. In a different semester, 20 students were either not working or not using any IT systems in their work environments. This introduced a unique challenge and resulted in offering three options for these two students' cohorts to complete the assignment. We decided (1) to use Practice Fusion ${ }^{\circledR}$ as one of the free-access comprehensive electronic health records. The instructor attempted to obtain access for these two cohorts of students in order to use Practice Fusion by contacting the system support team, but time constrains worked against that. These students were asked to review all available tutorials and modules on Practice Fusion website, identify a business process they are interested in and is related to their program of study, and find an IT-related gap in the system. Students were also given the options to (2) search for and select other free-access IT applications, or (3) use the IT system available in the institutes where they were completing their clinical practice during the semester. The latter was conditional to having a previous experience with the IT system in their previous workplace and within the last two years. In this case, students were also encouraged to contact the IT department and work with a nurse partner from the clinical setting to obtain details on system use. All students managed to identify a problem statement and to successfully complete the assignment. Five of the students picked option 3 to complete the assignment. On the other hand, this situation required the course instructor to create three different grading rubrics: one for students who currently work and have access to IT, one for students who currently work but do not use patient care technologies, and a third for students who currently do not work.

Course modification should be a continuous improvement process guided by new trends in heath and science as well as students' needs, feedback and success in completing learning activities. Finding many students unaware of the available IT resources including informatics experts in their institutes was an eye opener for students and the course instructor. As a result, the instructor is planning to add "IT Structure" as another step in Phase 1 of the project for students to better understand IT structure within their organizational chart.

Although the skills learned in the IT-related BPR assignment were extremely useful for our students in three different graduate programs, the adoption of this assignment and the pedagogical methods by other schools of nursing is necessary to evaluate its generalizability to other schools, students, and informatics educators. The integration of this assignment in informatics courses of other schools of nursing is manageable with the availability of informatics faculty. For informatics educators, the skills necessary to teach this assignment are part of the Nursing Informatics Scope and Standards of Practice defined by the American Nurses Association [30].

In summary, this paper described the methodology of designing, delivering and evaluating an IT-related BPR project as one of the main assignments in an introductory informatics course offered for graduate nursing students in three programs. Although the main objective of the assignment was to equip students with necessary skills to lead IT projects, the assignment touched on all other competencies recommended by the Institute of Medicine [2]. Students utilized latest evidence to support their problem statement and developed their improvement plan for a quality improvement initiative. Developing a connection with other departments was essential to better identify an IT-related problem and design an improvement plan in order to improve quality, safety and workflow. Following an organized systemic thinking of the BPR framework was a key for assignment success. 


\section{Limitations}

The use of un-anonymous reflective journal for course evaluation as one of the course requirement might have introduced bias. On the other hand, this method was very helpful to obtain detailed comments from all students. Students completed the course evaluation at the end of the course and after receiving all grades of all learning activities, were encouraged to provide objective feedback, and were reassured that the evaluation will be used only for future course improvement. Additionally, although less than half of the students anonymously evaluated the course using the IDEA system, the overall perceptions students provided in the free-text area in IDEA support their satisfaction with the course and teaching methods. Second, the reflective journal for course evaluation was based on general questions that did not target each course assignment. Although students provided detailed answers to all questions, evaluating the benefits and challenges of each assignment separately could be more helpful to guide assignment redesign.

\section{Conclusion}

Designing a student-centered applied assignment based on a systemic thinking approach and Programs Essentials is a successful approach for technical and professional development in informatics. Empowering students as process owners via IT and leadership skills and tools is necessary for knowledge transfer and understanding the complexity of change processes. Course modification is a continuous improvement process guided by new trends in health and science, as well as students' needs, feedback and success in completing learning activities.

\section{Acknowledgement}

We thank Dr. Cheryl Lehman, a retired professor from the School of Nursing University of Texas Health Science Center San Antonio for reviewing this paper.

\section{References}

1. American Health information Management Association \& American Medical Informatics Association (2006) Building the workforce for health information transformation

2. Institute of Medicine (2003) Health professions education: A Bridge to quality. Washington, DC: National Academies Press.

3. Informatics Guiding Education Reform (2008) The TIGER Initiative: Informatics competencies for every practicing nurse: Recommendations from the TIGER collaborative.

4. Staggers N, Gassert CA, Curran C (20011) Informatics competencies for nurses at four levels of practice. J Nurs Educ 40: 303-316.

5. Hart MD (2010) A Delphi study to determine baseline informatics competencies for nurse managers. Comput Inform Nurs 28: 364-370.

6. American Association of Colleges of Nursing (2006) Essentials of doctoral education for advanced nursing practice. Washington DC.

7. National Organization of Nurse Practitioner Faculties (2011) Nurse practitioner core competencies.

8. Friedman CP, Altman RB, Kohane IS, McCormick KA, Miller PL, et al. (2004) Training the next generation of informaticians: The impact of "BISTI" and bioinformatics-A Report from the American College of Medical Informatics. J Am Med Inform Assoc 11: 167-172.

9. Ritko AL, Odlum M (2013) Gap analysis of biomedical informatics graduate education competencies. AMIA Annu Symp Proc 1214-1223.
10. Kulikowski CA, Shortliffe EH, Currie LM, Elkin PL, Hunter LE, et al. (2012) AMIA Board white paper: Definition of biomedical informatics and specification of core competencies for graduate education in the discipline. J Am Med Inform Assoc 2012; 19: 931-938.

11. Choi J, De Martinis JE (2013) Nursing informatics competencies: Assessment of undergraduate and graduate nursing students. J Clin Nurs 22: 1970-1976.

12. Pravikoff D, Tanner A, Pierce S (2005) Readiness of U.S. nurses for evidencebased practice: Many don't understand or value research and have had little or no training to help them find evidence on which to base their practice. Am J Nurs 105: 40-51.

13. Fulton CR, Meek JA, Walker PH (2014) Faculty and organizational characteristics associated with Informatics/health information technology adoption in DNP programs. J Prof Nurs 30: 292-299.

14. Beckham R, Riedford K (2014) Evolution of a graduate-level informatics course for the noninformatics specialist nurse. JNP 10: 387-392.

15. Choi J, Zucker DM (2013) Self-assessment of nursing informatics competencies for doctor of nursing practice students. J Prof Nurs 29: 381- 387.

16. Jenkins M, Wilson M, Ozbolt $J$ (2007) Informatics in the doctor of nursing practice curriculum. AMIA Annu Symp Proc 364-368.

17. Hammer M, Champey J (2006) Re-engineering the corporation. A Manifesto for Business Revolution, Harper Business New York.

18. Dedhia NS, Six Sigma Basics (2005) Total Qual Manage 16: 567-574

19. Yarmohammadian MH, Ebrahimipour H, Doosty F (2014) Improvement of hospital processes through business process management in Qaem Teaching Hospital: A work in progress. J Educ Health Promot 29: 111.

20. Poomkothammal V (2006) Business process study simulation for resource management in an emergency department. Stud Health Technol Inform 122: 1041-1042.

21. Dickhaus CF, Burghart C, Tempany C, D'Amico A, Haker S, et al. (2004) Workflow modeling and analysis of computer guided prostate brachytherapy under MR imaging control. Stud Health Technol Inform 98: 72-74.

22. Rosemann M, Bruin T (2005) Application of a holistic model for determining BPM maturity. BP Trends 1-21.

23. Cronenwett L, Sherwood G, Pohl J, Barnsteiner J, Moore S, et al. (2009) Quality and safety education for advanced nursing practice. Nurs Outlook 57: 338-348.

24. Adesola S, Baines T (2006) Developing and evaluating a methodology for business process improvement. BPMJ 11: 37-46.

25. Harrison JP (2010) Essentials of strategic planning in healthcare. Foundation of the American College of Healthcare Executives, USA.

26. Alter S (2013) Work system theory: Overview of core concepts, extensions, and challenges for the future. JAIS 14: 72-121.

27. Sowan AK, Jenkins LS (2013) Designing, delivering and evaluating a distance learning nursing course responsive to student's needs. Int J Med Inform 82: 553-564.

28. Anderson J, Gremy F, Pages J (1974) Education in informatics of health professionals. New York: Elsevier Publishing

29. National League for Nursing (2008) Preparing the next generation of nurses to practice in a technology-rich environment: An informatics agenda 1-6.

30. American Nurses Association (2014) Nursing informatics scope and standards of practice. Silver Spring, MD, NursesBooks.org.

Copyright: () 2015 Sowan AK. This is an open-access article distributed under the terms of the Creative Commons Attribution License, which permits unrestricted use, distribution, and reproduction in any medium, provided the original author and source are credited. 